\title{
Carboxymethylchitosan nanofibers containing silver nanoparticles: Preparation, Characterization and Antibacterial activity
}

\author{
Hassan M. Ibrahim ${ }^{1 *}$, Enas M.R. El- Zairy ${ }^{2}$ \\ ${ }^{1}$ Pre-Treatment \& Finishing of Cellulosic Fibers, Textile Research Division, National Research Centre, 33 El Bohouth st. (Former El Tahrir St.), Dokki, \\ Giza, Egypt, P.O.12622. ${ }^{2}$ Faculty of Applied Arts, Printing, Dyeing and Finishing Dept., Helwan Univ., Cairo, Egypt.
}

\section{ARTICLE INFO}

Article history:

Received on: 28/01/2016

Revised on: 17/03/2016

Accepted on: 18/05/2016

Available online: $28 / 07 / 2016$

Key words:

Carboxymethylchitosan, nanofibers, silver nanoparticles, antibacterial, biological application.

\begin{abstract}
Herein we prepare antibacterial composite from carboxymethylchitosan (CMCS) nanofibers and silver nanoparticles (AgNPs) by using poly (vinyl alcohol) (PVA) as reducing, capping and fiber aiding material and investigated to be used in biomedical applications. The AgNPs has spherical shapes and its diameter ranged from 15 to $25 \mathrm{~nm}$ and distributed within the prepared nanofibers. The electrospinning parameters from the effect of the CMCS and PVA mass ratio, extrusion rate and field were studied. The optimum condition for electrospinning were 7\% for CMCS and 8\% from PVA. UV-vis, TEM and XRD used to characterize AgNPs whereas FTIR and SEM used to characterize nanofibers. Results showed that ultra-fine fibers were generated after addition of PVA to CMCS in different mass ratios to from $8 \mathrm{wt}$ \% concentration solutions. Electrospun PVA (AgNPs)/CMCS nanofibers showed good antibacterial effects towards Gram-positive and Gram-negative bacteria. Antibacterial activities of electrospun nanofibers increased by increasing both CMCS and AgNPs content in the electrospun nanofibers.
\end{abstract}

\section{INTRODUCTION}

Chitosan polymer composed of glucosamine and 2acetyl glucosamine units and it is one of the most few nitrogen containing natural polysaccharides that has antibacterial properties(Rinaudo, 2006). It is soluble in acids, so that it exhibit antibacterial activity appears in an acidic medium only. In addition its electrospun nanofibers produced from acetic acid, formic acid and trifluoroacetic acid (Duan et al., 2004; Ohkawa et al., 2004; Park et al., 2004; Bhattarai et al., 2005; Li and Hsieh, 2006; Jia et al., 2007; Du and Hsieh, 2008). The produced electrospun fibers contains traces of acids or organic solvents which are harmful, reduced its biocompatibility and increase its toxicity. To overcome these problems, carboxymethylchitosan was produced as water-soluble chitosan derivative to obtain

* Corresponding Author

Hassan M. Ibrahim, Pre-Treatment \& Finishing of Cellulosic Fibers, Textile Research Division, National Research Centre, 33 El Bohouth st. (Former El Tahrir St.), Dokki, Giza, Egypt.

Email:hmaibrahim@gmail.com nanofibers from water and then increase its biomedical and biological applications (Chen et al., 2006; Abou-Zeid et al., 2013). Silver metal and its ions can interact with the thiol groups of enzyme and proteins and transport vital substances outside bacterial membrane without affect the human cell. So that it has wide range of bactericidal activity towards Gram-positive and Gram-negative bacteria. The surface area of silver nanoparticles higher than that of silver metal so that it has higher antibacterial activity than silver metal.(Maneerung et al., 2008; Yang et al., 2012). Glucose is a soft reducing agent used to reduce Silver nitrate to silver nanoparticles and it is widely used in biomedical processes.

PVA is a safe poly reducing agent for silver ions and fiber aiding material for carboxymethylchitosan due to it is nontoxic and stable towards chemicals(Acatay et al., 2004; Yang et al., 2004; Zhang et al., 2007). Fiber formation from polymer solutions via electrospinning process depends on electrical high voltage, the distance from tip-to-collector and the rate of extrusion of polymer solution (Deitzel et al., 2001; Frenot and Chronakis, 2003; Sun and Li, 2011). 
Electrospinning is a very effective, simple and inexpensive method of producing nanofibers from its polymer solution compared to other methods such as self-assembly and phase separation and has the potential for large-scale manufacturing (Jayaraman et al., 2004; Zhang et al., 2007). The nanofibers have very large surface area so that it is compatible with human cells' size and suitable to form products for filtration of sub-particles, adsorption of biological and chemical warfare gases, medical industry as artificial blood vessels and organs, sutures, surgical facemask, wound dressing, and drug delivery systems (Mohan, 2003; Bhattarai et al., 2005).

The aim of this work to prepare colloidal silver nanoparticles by using PVA/glucose redox system and then impregnated these nanoparticles within CMCS nanofibers by using electrospinning technique to produce antibacterial nanofibers. UV absorption, XRD and TEM micrograph used to investigate the prepared silver nanoparticles (AgNPs). FTIR and SEM micrograph were used to characterize the produced nanofibers. Finally evaluate its antibacterial activity to be used in biomedical applications.

\section{MATERIALS AND METHODS}

Chitosan (CS) (Aldrich, USA, viscosity 1860cps, degree of deacetylation 79.0\%). PVA (Fine Chemicals Pvt. Ltd, India, MW 88,000, degree of deacetylation $89 \%$ and viscosity $35-50 \mathrm{cps}$ for $4 \%$ solution at $20{ }^{\circ} \mathrm{C}$ ). $\mathrm{AgNO}_{3}$ (Sigma Chemical Co., USA) All other chemicals and reagents were of analytical grade, and used without further purification

Staphylococcus aureus (S. aureus) as Gram-positive bacteria and Escherichia coli (E. coli)as Gram-negative bacteria used for the antibacterial assay were provided from Antibacterial lab, Faculty of Girls for Arts, Science and Education, Ain Shams University, Cairo, Egypt.

The carboxymethylchitosan (CMCS) was prepared as reported method mentioned elsewhere(Abou-Zeid et al., 2013; Ibrahim et al., 2015b).

Silver nanoparticles (AgNPs) were prepared by the reduction of silver nitrate by using PVA/glucose as reducing agent (Mbhele et al., 2003). Briefly, $\mathrm{AgNO}_{3}$ samples (0.1 M, 0.01 M and $0.001 \mathrm{M})$ were added to PVA solution (1, 3, $6 \mathrm{wt}$ \%)in the presence of glucose as reducing agent and to prevent the oxidation of $\mathrm{AgNO}_{3}$ to $\mathrm{Ag}_{2} \mathrm{O}$. Formation of clear yellow to brownish yellow colour indicated that AgNPs formed and ready to use.

Polymer solutions used for electrospinning were prepared as follow: CMCS solution (7 wt. \%), was prepared by dissolving $0.7 \mathrm{~g}$ of CMCS in $10 \mathrm{ml}$ distilled water under continues stirring for 1 hour. PVA solution containing $\operatorname{Ag} \operatorname{NPs}(8$ wt.\%) was prepared by dissolving $0.8 \mathrm{~g}$ of PVA in $10 \mathrm{ml}$ distilled water with moderate stirring at $60{ }^{\circ} \mathrm{C}$ for $2 \mathrm{hr}$., then add to this solution different concentration of $\mathrm{AgNO}_{3}(0.001,0.01$ and $0.1 \mathrm{M})$ in the presence of glucose $(0.15 \mathrm{gm} / 10 \mathrm{ml})$ for $72 \mathrm{hrs}$. The optimum condition for forming nanofibers is $8 \mathrm{wt}$ \% PVA and $7 \mathrm{wt}$ \% CMCS solution from 8 wt. \% solution, obtained from our previous work(Ibrahim et al., 2015a).

The electrospinning device used consists mainly of extrusion system (syringe pump), collecting electrode, and high voltage supply as shown in Figure 1. Experimental design of the electrospinning process of CMC containing AgNPs are shown in Table 1.

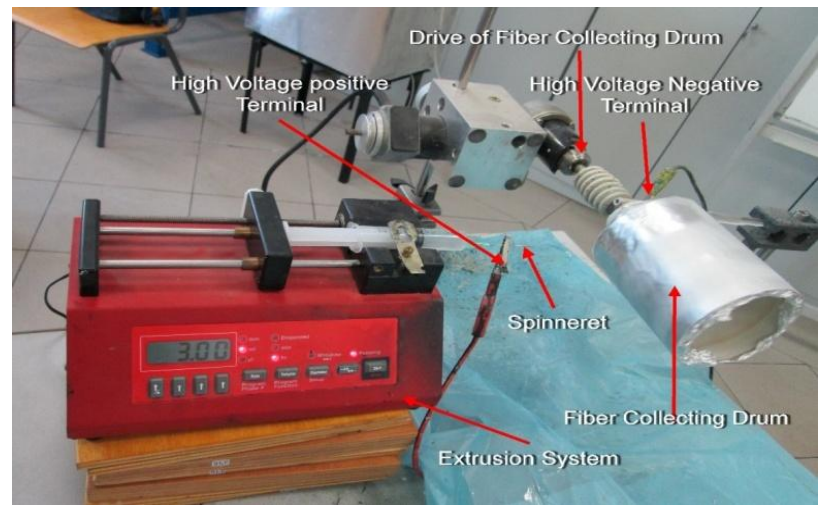

Fig. 1: Electrospinning equipment

Table. 1: electrospinning Design of PVA/AgNPs/CMCS.

\begin{tabular}{lcccc}
\hline $\begin{array}{c}\text { PVA/AgNPs/C } \\
\text { MCS,W/W }\end{array}$ & $\begin{array}{c}\text { Potential, } \\
\mathbf{k v}\end{array}$ & $\begin{array}{c}\text { Distance, } \\
\mathbf{c m}\end{array}$ & $\begin{array}{c}\text { Field, } \\
\mathbf{k v} / \mathbf{c m}\end{array}$ & $\begin{array}{c}\text { Extrusion } \\
\text { Rate, } \mathbf{~ m l} / \mathbf{h r}\end{array}$ \\
\hline $100 / 00$ & 30 & 6,10 & 3,5 & 1,3 \\
$75 / 25$ & 30 & 6,10 & 3,5 & 1,3 \\
$50 / 50$ & 30 & 6,10 & 3,5 & 1,3 \\
$25 / 75$ & 30 & 6,10 & 3,5 & 1,3 \\
$00 / 100$ & 30 & 6,10 & 3,5 & 1,3 \\
\hline
\end{tabular}

The morphology and particle size of Ag-NPs were investigated by using, transmission electron microscope (TEM), JEOL JEM $2100 \mathrm{~F}$ electron microscope at $200 \mathrm{kv}$. The surface morphology of the electrospun nanofibers were investigated by scanning electron microscope (SEM) examination by mounting the samples on stub with double stick adhesive tape and coated with gold in a S150A sputter coater unit (Edwards, UK). The gold film thickness was $150 \mathrm{~A}^{\circ}$. The samples were then viewed in a JEOL JXA-950 electron probe micro analyzer, Japan. UV-Vis absorption spectra of AgNPs were recorded by using a Spectronic UV-Vis spectrometer (Model: Genesys 2, USA). Fourier transform infrared (FT-IR) spectra of the all samples were obtained using a Nexus 670 FT-IR spectrophotometer (Lelet Co., USA). The spectra of sample in the range of $4000-800 \mathrm{~cm}^{-1}$ are investigated. X-ray diffraction studies were conducted using an Xray diffractometer (D2 Phaser, Bruker AXS, Germany) operating at $30 \mathrm{kV}$ and $10 \mathrm{~mA}$. The diffraction patterns were recorded using $\mathrm{Cu}-\mathrm{K}$ radiation and the film samples were analyzed at a 2 range, $1-50$.

The antibacterial activity of the prepared nanofibers were determined by disk diffusion method on an agar plate (Abou-Zeid et al., 2011; Ibrahim et al., 2015a). In the antibacterial assay, all data were the means from at least three parallel experiments that the discrepancies among them were less than $5 \%$. 


\section{RESULTS AND DISCUSSION}

\section{Preparation of silver nanoparticles}

On using PVA in the presence of glucose as reducing agent of silver nitrate to form silver nanoparticles large clusters disappears and clear spherical particles formed so that PVA used as capping agent and reducing agent at the same time.

Silver nitrate reduced into silver nanoparticles in aqueous solution and these nano particles have UV-vis absorption peak at $430 \mathrm{~nm}$ due to free electrons excitation(Temgire and Joshi, 2004). When $\mathrm{AgNO}_{3}$ is mixed with PVA solution, the electropositivity of $\mathrm{Ag}^{+}$ions allow it to bind with PVA through electrostatic forces, which change the colour of PVA solution fromcoluorless to yellow and brownish yellow in the presence of glucose(Nguyen et al., 2010).

Silver ions/PVA undergo redox system where; the $\mathrm{OH}$ groups of PVA converted into $\mathrm{C}=\mathrm{O}$ groupsat the same time $\mathrm{Ag}^{+}$ converted into $\mathrm{Ag}^{0}$. Also, glucose acts as co-reducing agent with PVA through its free aldehydic groups as mentioned elsewhere in previous work for natural biopolymers (Hebeish et al., 2010; Abdel-Halim and Al-Deyab, 2011).
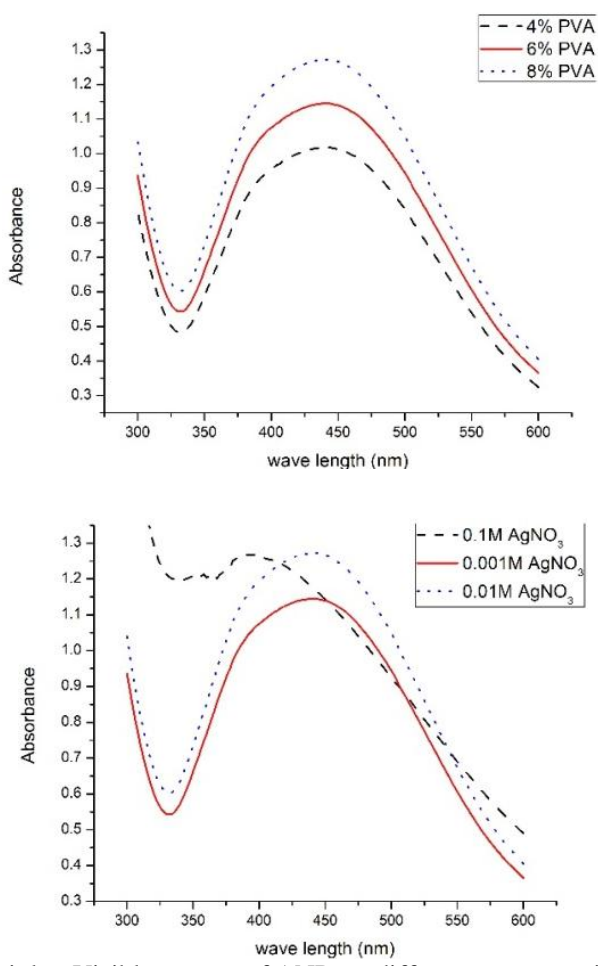

Fig. 2: Ultraviolet-Visible spectra of ANPs at different concentrations.

The formation of silver nanoparticles we achieved by UV-Vis. Absorption peaks at $\sim 430 \mathrm{~nm}$ as shown in figure 2. . Figure2a shows the effect of different PVA concentrations $(3,6,8$ wt. \%)on silver nanoparticles formation at constant $\mathrm{AgNO}_{3}$ concentration at $0.001 \mathrm{M}$. UV-vis. spectra shows that formation of Silver stabilized by increasing of PVAwt. \%. Although the maximum peak position and size didn't change, due to the coordination bond between oxygen n-electrons of PVA and silver $\left(\mathrm{Ag}^{+}\right.$and $\left.\mathrm{Ag}^{0}\right)(\mathrm{Jin}$ et al., 2007). Figure2b illustrate the effect of silver nitrate concentration $(0.001 \mathrm{M}-0.1 \mathrm{M})$ at constant PVA concentration (6wt. \%) and this change monitored by UV-Vis. Spectra. The UV-Vis peak intensity and formation of spherical shaped of AgNPs increased as $\mathrm{AgNO}_{3}$ concentration decreased(Petica et al., 2008).
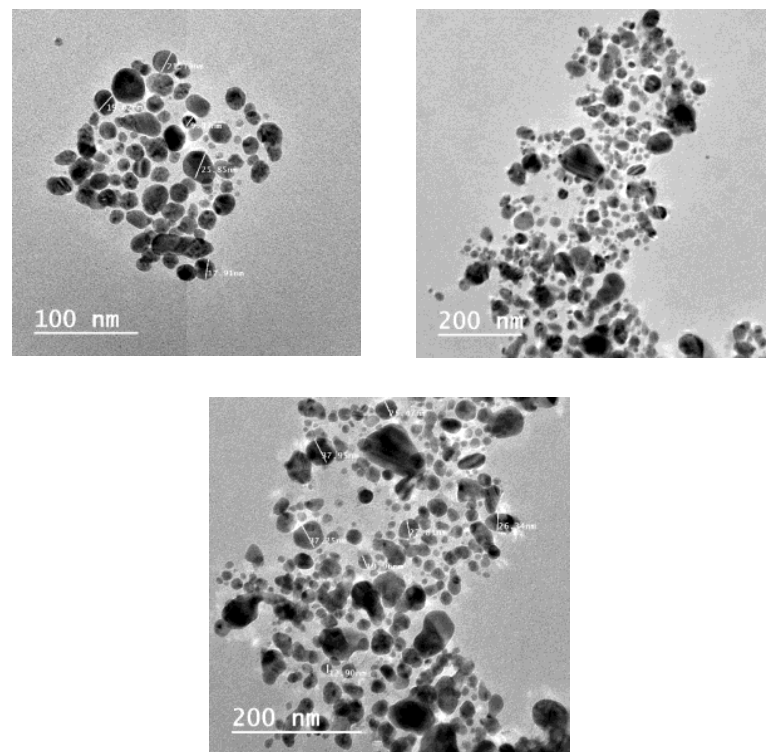

Fig. 3: TEM micrographs of AgNPs obtained in the presence of $6 \mathrm{~g} / 100 \mathrm{ml}$ aqueous solution (a), $0.001 \mathrm{M} \mathrm{AgNO}_{3}$ (b) $0.01 \mathrm{M} \mathrm{AgNO}_{3}$ (c).0.1 $\mathrm{M} \mathrm{AgNO}_{3}$

Figure 3 shows that the images of AgNPs by TEM, which proof that these nanoparticles has spherical shapes, uniform scattered and its diameter ranged from 15-25 nm. In addition, aggregation of the particles associated with an increasing of $\mathrm{AgNO}_{3}$ concentrations.

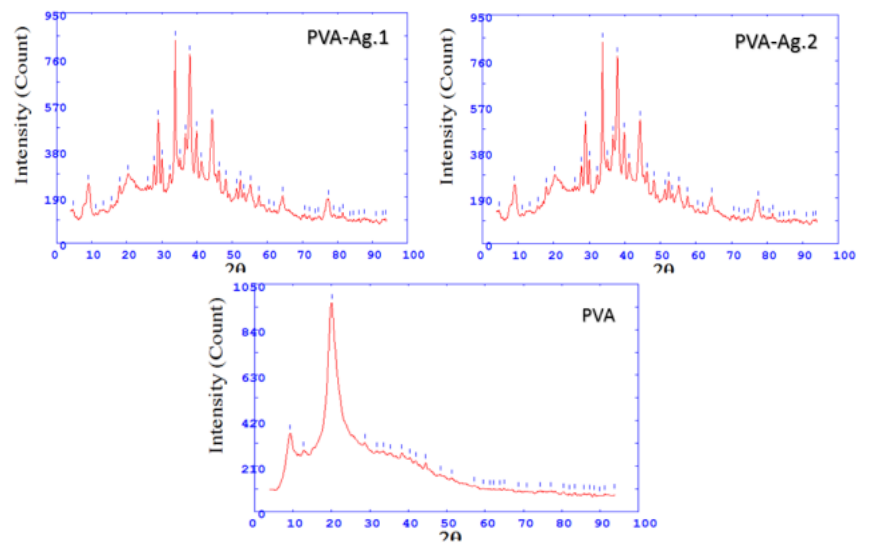

Fig. 4: XRD pattern of PVA and AgNps;

Crystalline behavior of PVA nanofibers containing AgNPs was confirmed by using XRD. XRD profiles of PVA nanofibers loaded AgNPs by electrospinning and pure PVA nanofibers using electrospinning technique are showed in Figure 4. Diffraction peak corresponds to crystallization of silver nanoparticles present at $(2 \theta=38)$ which can differentiate between pure PVA nanofibers from PVA nanofibers containing AgNPs (figure 4) (Ricciardi et al., 2005; Nguyen et al., 2010). 


\section{Electrospinning of PVA/AgNPs/CMCS aqueous solutions}

Carboxymethylchitosan (CMCS) is polyelectrolyte have high viscosity so that its water solution is not be easily electrospun alone but it need to blends with another polymer as aiding fiber formation to form nanofibers. Polyvinyl alcohol (PVA) act as a "guest" polymer due to it can form hydrogen bonding with CMCS and could be electrospun from its aqueous solutions. In addition, PVA used as both reducing and capping agent for AgNPs as we discussed before. In previous study (Ibrahim et al., 2015a) we concluded that $7 \%$ CMCS concentration showed more uniform nanofiber morphology. Therefore, 7\% wt., CMCS concentration mixed with PVA containing AgNPs to get antibacterial nanofibers used in biomedical applications. The morphology of prepared nanofibers characterized by SEM imagesas we seen in Figure 5. When CMCS percentage is $100 \%$ we obtain beads with films as seen in figure 5a. As the percent of PVA containing AgNPs increased the beads formation starts disappears with appears fibers as seen in figure $5 \mathrm{~b}$ and $5 \mathrm{c}$., and as the percent increased more than $50 \%$ the beads were completely disappear and we got nanofibers appears as seen in figure 5d and 5e.(Zhou et al., 2007; Ibrahim et al., 2015a).
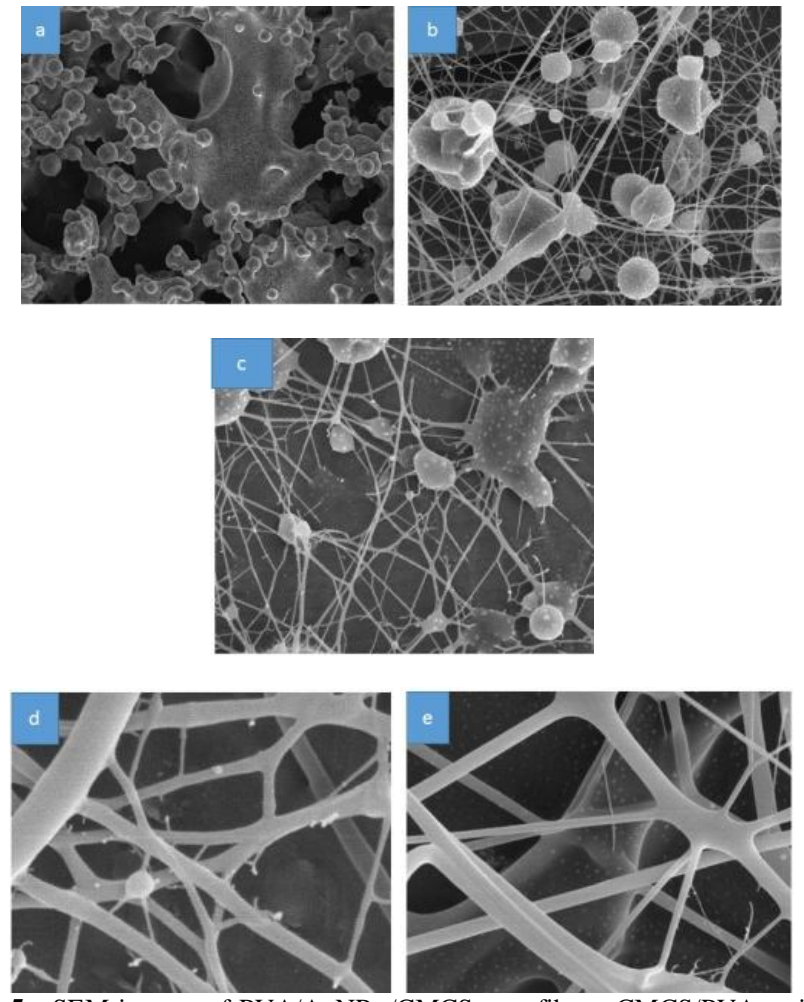

Fig. 5: SEM images of PVA/AgNPs./CMCS nanofibers. CMCS/PVA weight ratio: (a) $100 / 00$; (b) $75 / 25$; (c) $50 / 50$; (d) $25 / 70$; (e) $00 / 100$ at $1 \mathrm{ml} / \mathrm{h}$. extrusion rate and $(30 \mathrm{Kv} / 10 \mathrm{~cm})$ field

Figure 6 shows the FTIR of the pure PVA, pure CMCS and PVA-AgNPs-CMCS nanocomposites (Mbhele et al., 2003). Disappearance of 837 and 711,650 , and $570 \mathrm{~cm}^{-1}$ spectral bands for out of plane $\mathrm{CH}$ and $\mathrm{OH}$ groups respectively indicate that AgNPs increased in the composite and it react with CMCS through $\mathrm{OH}$ groups. Also AgNPs oriented within CMCS chains illustrated by appearing bands at $1322 \mathrm{~cm}^{-1}$ from coupling of $\mathrm{OH}$ in plane and at $1420 \mathrm{~cm}^{-1}$ form $\mathrm{CH}$ wagging vibrations.

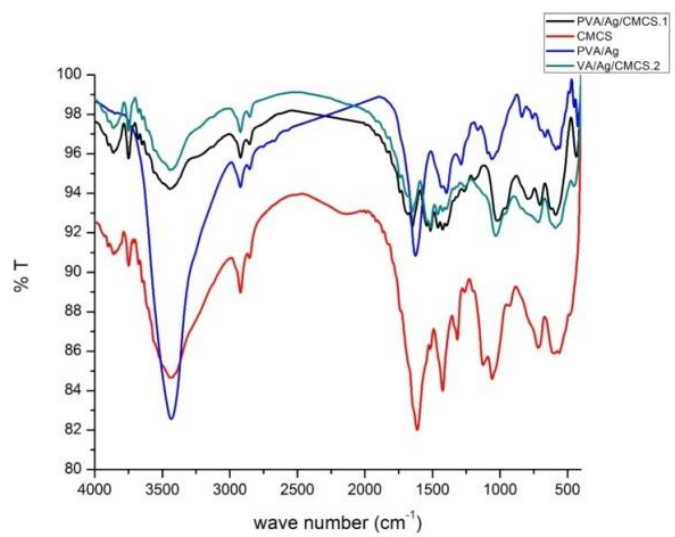

Fig. 6: FTIR spectra of CMCS, PVA-AgNPs and PVA-AgNPs-CMCS nanofibers.

\section{Antibacterial activity of PVA (AgNPs) CMCS nanofiber composites}

Figure 7 shows the antibacterial activity expressed in inhibition zone of the electrospun carboxymethylchitosan, according to the disk diffusion method, on Gram-positive and Gram-negative bacteria as mentioned in the experimental section.
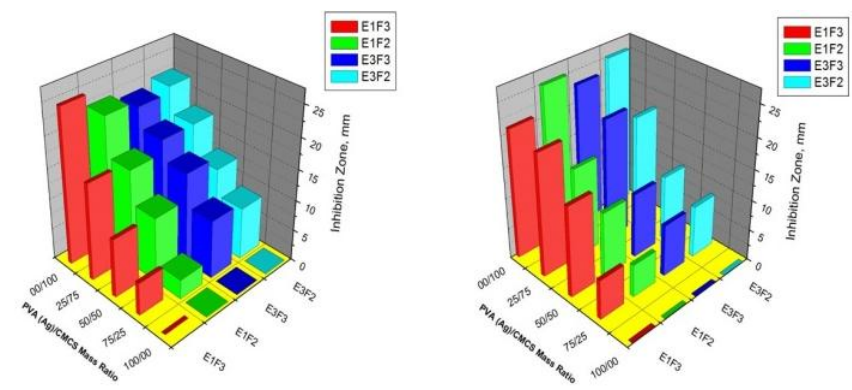

Effect of mass ration on Gram (+) bacterial

Effect of mass ration on Gram (-) bacterial

$\mathrm{E}=$ extrusion rate $(\mathrm{ml} / \mathrm{hr}$.) and $\mathrm{F}=$ Field $(\mathrm{Kv} / \mathrm{cm})$

Fig. 7: Effect of PVA and CMCS Ratio on antibacterial activity. E: Extrusion rate and F: Electric Field.

Chitosan used as wound dressing because it is bactericidal material and its antibacterial mechanism explained through the reaction between chitosan $\mathrm{NH}_{2}$ groups and bacterial cell membrane and then its growth inhibited, bacterial cell death or transfer its components outside the bacterial cell.(Helander et al., 2001; Ghoujegh and Mousavi, 2002).

From figure 7 , we found that the antibacterial activity of the nanofibers increased as CMCS ratio increased which indicate that the reaction with CMCS and AgNPs takes place at $\mathrm{OH}$ groups not $\mathrm{NH}_{2}$ groups. In other words, the area covered by the nanofibers from CMCS higher with concentration a matter that lead to an increase of the inhabitation zone with concentration(Seyam et al., 2012; Ibrahim et al., 2015a).

Although chitosan had more effective towards Grampositive bacteria than gram-negative bacteria due to cell membrane 
of bacteria (Abou-Zeid et al., 2011). However, previous results shows that electrospun carboxymethylchitosan nanofibers shows the similar antibacterial activity towards both Gram-positive and Gram-negative bacteria due to its transform to nano structure that made it able to penetrate the bacterial cell wall even it had potential barrier. (Seyam et al., 2012; Ibrahim et al., 2015a).

As shown in Figure7, the changing of extrusion rate from 1 to $3 \mathrm{ml} / \mathrm{h}$ and the changing of the needle tip-to-collector distance didn't affect the morphology and the antibacterial activity of the electrospun nanofibers because the amount of both CMCS and AgNPs in nanofiber web deposit at the collectors are the same (Seyam et al., 2012; Ibrahim et al., 2015a).

\section{CONCLUSION}

Antibacterial composite from carboxymethylchitosan (CMCS) nanofibers and silver nanoparticles (AgNPs) by using poly (vinyl alcohol) (PVA) were prepared. Antibacterial activities of electrospun nanofibers increased by increasing of both CMCS and Ag nanoparticles percent in the electrospun membrane and showed good antibacterial effects towards Gram (+ve) and Gram (-ve) bacteria. Also, we can used it as biomedical application. PVA act as reducing, capping and fiber aiding material. The prepared AgNPs has spherical shapes and its diameter ranged from 15 to $25 \mathrm{~nm}$ and distributed within the prepared nanofibers.

\section{ACKNOWLEDGEMENT}

The authors gratefully acknowledges National Research Centre, for financial support and for facilities provided through project ID: 10050309.

\section{REFERENCES}

Abdel-Halim E and Al-Deyab SS. Utilization of hydroxypropyl cellulose for green and efficient synthesis of silver nanoparticles. Carbohydrate Polymers, 2011; 86 (4): 1615-1622.

Abou-Zeid NY, Waly AI, Kandile NG, Rushdy AA, El-Sheikh MA and Ibrahim HM. CARBOXYMETHYLCHITOSAN/VISCOSE BLENDEDFILMS: PREPARATION, CHARACTERIZATIONAND ANTIBACTERIAL PROPERTIES. Journal of Materials Science and Engineering with Advanced Technology, 2013; 7 (2): 93-123.

Abou-Zeid NY, Waly AI, Kandile NG, Rushdy AA, El-Sheikh MA and Ibrahim HM. Preparation, characterization and antibacterial properties of cyanoethylchitosan/cellulose acetate polymer blended films. Carbohydrate Polymers, 2011; 84 (1): 223-230.

Acatay K, Simsek E, Ow-Yang C and Menceloglu YZ. Tunable, superhydrophobically stable polymeric surfaces by electrospinning. Angewandte Chemie International Edition, 2004; 43 (39): 5210-5213.

Bhattarai N, Edmondson D, Veiseh O, Matsen FA and Zhang M. Electrospun chitosan-based nanofibers and their cellular compatibility. Biomaterials, 2005; 26 (31): 6176-6184.

Chen R-N, Wang G-M, Chen C-H, Ho H-O and Sheu M-T. Development of N,O-(Carboxymethyl)chitosan/Collagen Matrixes as a Wound Dressing. Biomacromolecules, 2006; 7 (4): 1058-1064.

Deitzel JM, Kleinmeyer JD, Hirvonen JK and Beck Tan NC. Controlled deposition of electrospun poly (ethylene oxide) fibers. Polymer, 2001; 42 (19): 8163-8170.

Du J and Hsieh Y-L. Nanofibrous membranes from aqueous electrospinning of carboxymethyl chitosan. Nanotechnology,2008;19 (12):
Duan B, Dong C, Yuan X and Yao K. Electrospinning of chitosan solutions in acetic acid with poly(ethylene oxide). Journal of Biomaterials Science, Polymer Edition, 2004; 15 (6): 797-811.

Frenot A and Chronakis IS. Polymer nanofibers assembled by electrospinning. Current Opinion in Colloid \& Interface Science, 2003; 8 (1): 64-75.

Ghoujegh D and Mousavi SE. ANTIBACTERIAL ACTIVITY OF CHITOSAN AGAINST ESCHERICHIA COLI. YAKHTEH, 2002:

Hebeish A, El-Rafie M, Abdel-Mohdy F, Abdel-Halim E and Emam HE. Carboxymethyl cellulose for green synthesis and stabilization of silver nanoparticles. Carbohydrate Polymers, 2010; 82 (3): 933-941.

Helander IM, Nurmiaho-Lassila EL, Ahvenainen R, Rhoades J and Roller S. Chitosan disrupts the barrier properties of the outer membrane of Gram-negative bacteria. International journal of food microbiology, 2001; 71 (2): 235-244.

Ibrahim H, Dakrory A, Klingner A and El-Masry A. Carboxymethyl Chitosan Electrospun Nanofibers: Preparation and its Antibacterial Activity. Journal of Textile \& Apparel Technology \& Management (JTATM), 2015a; 9 (2):

Ibrahim H, El-Zairy $E$ and Mosaad R. Preparation, characterization and median lethal dose (LD50) of carboxymethyl chitosan as target Drug Delivery. International Journal, 2015b; 3 (1): 865-873.

Jayaraman K, Kotaki M, Zhang Y, Mo X and Ramakrishna S. Recent advances in polymer nanofibers. Journal of Nanoscience and Nanotechnology, 2004; 4 (1-2): 1-2.

Jia Y-T, Gong J, Gu X-H, Kim H-Y, Dong J and Shen X-Y. Fabrication and characterization of poly (vinyl alcohol)/chitosan blend nanofibers produced by electrospinning method. Carbohydrate Polymers, 2007; 67 (3): 403-409.

Jin W-J, Jeon HJ, Kim JH and Youk JH. A study on the preparation of poly (vinyl alcohol) nanofibers containing silver nanoparticles. Synthetic Metals, 2007; 157 (10): 454-459.

Li L and Hsieh Y-L. Chitosan bicomponent nanofibers and nanoporous fibers. Carbohydrate research, 2006; 341 (3): 374-381.

Maneerung $\mathrm{T}$, Tokura $\mathrm{S}$ and Rujiravanit $\mathrm{R}$. Impregnation of silver nanoparticles into bacterial cellulose for antimicrobial wound dressing. Carbohydrate Polymers, 2008; 72 (1): 43-51.

Mbhele Z, Salemane M, Van Sittert C, Nedeljkovic J, Djokovic $\mathrm{V}$ and Luyt A. Fabrication and characterization of silver-polyvinyl alcohol nanocomposites. Chemistry of Materials, 2003; 15 (26): 5019 5024 .

Mohan A. Formation and characterization of electrospun nonwoven webs. 2003:

Nguyen T-H, Lee K-H and Lee B-T. Fabrication of Ag nanoparticles dispersed in PVA nanowire mats by microwave irradiation and electro-spinning. Materials Science and Engineering: C, 2010; 30 (7): 944-950.

Ohkawa K, Cha D, Kim H, Nishida A and Yamamoto H. Electrospinning of chitosan. Macromolecular Rapid Communications, 2004; 25 (18): 1600-1605.

Park WH, Jeong L, Yoo DI and Hudson S. Effect of chitosan on morphology and conformation of electrospun silk fibroin nanofibers. Polymer, 2004; 45 (21): 7151-7157.

Petica A, Gavriliu S, Lungu M, Buruntea N and Panzaru C. Colloidal silver solutions with antimicrobial properties. Materials Science and Engineering: B, 2008; 152 (1): 22-27.

Ricciardi R, Auriemma F and De Rosa C (2005). Structure and properties of poly (vinyl alcohol) hydrogels obtained by freeze/thaw techniques. Macromolecular Symposia, Wiley Online Library.

Rinaudo M. Chitin and chitosan: properties and applications. Progress in polymer science, 2006; 31 (7): 603-632.

Seyam A-FM, Hudson SM, Ibrahim HM, Waly AI and AbouZeid NY. Healing performance of wound dressing from cyanoethyl chitosan electrospun fibres. Indian Journal of Fibre and Textile Research, 2012; 37 (3): 205

Sun K and Li ZH. Preparations, properties and applications of chitosan based nanofibers fabricated by electrospinning. Expr Polym Lett, 2011; 5 (4): 342-361. 
Temgire $\mathrm{M}$ and Joshi S. Optical and structural studies of silver nanoparticles. Radiation Physics and Chemistry, 2004; 71 (5): 1039-1044.

Yang G-C, Gong J, Pan Y, Cui X-J, Shao C-L, Guo Y-H, Wen $\mathrm{S}-\mathrm{B}$ and $\mathrm{Qu} \mathrm{L-Y}$. Preparation and photochromic properties of ultra-fine H3PW11MoO40/PVA fibre mats. Journal of Physics D: Applied Physics, 2004; 37 (14):

Yang G, Xie J, Hong F, Cao Z and Yang X. Antimicrobial activity of silver nanoparticle impregnated bacterial cellulose membrane: effect of fermentation carbon sources of bacterial cellulose. Carbohydrate Polymers, 2012; 87 (1): 839-845.

Zhang Y, Huang X, Duan B, Wu L, Li S and Yuan X. Preparation of electrospun chitosan/poly (vinyl alcohol) membranes. Colloid and Polymer Science, 2007; 285 (8): 855-863.
Zhou Y, Yang D, Chen X, Xu Q, Lu F and Nie J. Electrospun water-soluble carboxyethyl chitosan/poly (vinyl alcohol) nanofibrous membrane as potential wound dressing for skin regeneration. Biomacromolecules, 2007; 9 (1): 349-354.

\section{How to cite this article:}

Ibrahim HM, El-Zairy EMR. Carboxymethylchitosan nanofibers containing silver nanoparticles: Preparation, Characterization and Antibacterial activity. J App Pharm Sci, 2016; 6 (07): 043-048. 